\title{
Implementation of Forest Canopy Density Model to Monitor Forest Fragmentation in Mt. Simpang and Mt. Tilu Nature Reserves, West Java, Indonesia
}

\author{
Firman HADI, Ketut WIKANTIKA and Irawan SUMARTO, Indonesia
}

Key words: fragmentation, canopy, monitoring, Landsat, vegetation index

\section{SUMMARY}

Mt. Simpang and Mt. Tilu Nature Reserve which cover 23,000 hectares area, are the largest nature reserves in West Java (Whitten et al. 1996). Besides their important value as places of high biodiversity and as water towers, these reserves face severe threats due to habitat loss and fragmentation (MST 2000). Remote sensing has the ability to identify destructed and fragmented part of the reserves with the quickest and the most efficient way. In this research, Forest Canopy Density Model was used to detect the percentage of crown closures (canopy), which indicates the level of degradation. The model was used due to its independency from accuracy assessment. The result shows that FCD model was able to detect forest canopy within one type vegetation. It was not able to differentiate forest canopy among two types of vegetation. Teak plantation outside the reserves showed greater FCD value than natural forest. Further research which incorporates other parameters is needed to overcome this problem.

TS 21 - Taxation and Valuation 


\title{
Implementation of Forest Canopy Density Model to Monitor Forest Fragmentation in Mt. Simpang and Mt. Tilu Nature Reserves, West Java, Indonesia
}

\author{
Firman HADI, Ketut WIKANTIKA and Irawan SUMARTO, Indonesia
}

\section{INTRODUCTION}

Forest fragmentation is the process of cutting a large forest into a number of smaller pieces forests (WJU 2003). Fragmentation causes remnant vegetation patches to be situated in different positions in the landscape, varying in size, shape, isolation (Sunders et al. 1990).

Mt. Simpang and Mt. Tilu Nature Reserves which cover 23,000 hectares area, are the largest nature reserves in West Java (Whitten et al. 1996). Besides their important value as places of high biodiversity and as water towers, these reserves face severe threats due to habitat loss and fragmentation (MST 2000). To slow down the rate of fragmentation in these reserves, there has to be an effective monitoring system. Remote sensing applications are able to perform this task.

One of the method to assess the forest health through remote sensing application is the Forest Canopy Density Model. This method has been tested in large areas such as Sumatra and South Andaman. This research is intended to implement the Forest Canopy Density (FCD) model to monitor the forest fragmentation in relatively small areas such as Mt. Simpang and Mt. Tilu Nature Reserves, West Java, Indonesia.

\section{REVIEW OF FOREST CANOPY DENSITY MODEL}

Forest density expressing the stocking status constitutes the single major stand physiognomic characteristic of the forest. Satellite remote sensing provides a measure of the canopy closure. The percent crown closure is a measure of area occupation rather than stand density. However, it is an important parameter used to stratify the forests. Very few attempts have been reported to stratify the forest density using satellite remote sensing digital data (Roy et al. 1990).

Forest canopy density model, also known by Rikimaru's approach, was named after its inventor Atsushi Rikimaru who develop this method to monitor the forest health. The Forest Canopy Density (FCD) Mapping and monitoring Model utilized forest canopy density as an essential parameter for characterization of forest conditions. There is a relationship between canopy density and the dynamics of forest ecology. Dense canopies represent health forest while sparse or no canopies indicate the opposite. FCD is based on the growth phenomenon of forests and it can indicates the degree of degradation (Rikimaru et al. 1999).

The components of FCD model are four factors; vegetation, bare soil, thermal and shadow. The indices have some characteristics as below. The Forest Canopy Density Model combines data from the four (4) indices. Fig. 1 illustrates the relationship between forest conditions and the four indices (VI, BI, SI and TI). Vegetation index response to all of vegetation items such

TS 21 - Taxation and Valuation

Firman Hadi, Ketut Wikantika and Irawan Sumarto

TS21.4 Implementation of Forest Canopy Model to Monitor Forest Fragmentation in Mt. Simpang and Mt. Tilu Nature Reserves, West Java, Indonesia

$3^{\text {rd }}$ FIG Regional Conference

Jakarta, Indonesia, October 3-7, 2004 
as the forest and the grass land. Advanced vegetation index AVI reacts sensitively for the vegetation quantity compared with NDVI. Shadow index increases as the forest density increases. Thermal index increase as the vegetation quantity increases. Black colored soil area shows a high temperature. Bare soil index increases as the bare soil exposure degrees of ground increase. These index values are calculated for every pixel. Fig. 1 shows the characteristics of four indices compared with forest condition (Rikimaru and Miyatake 1997).

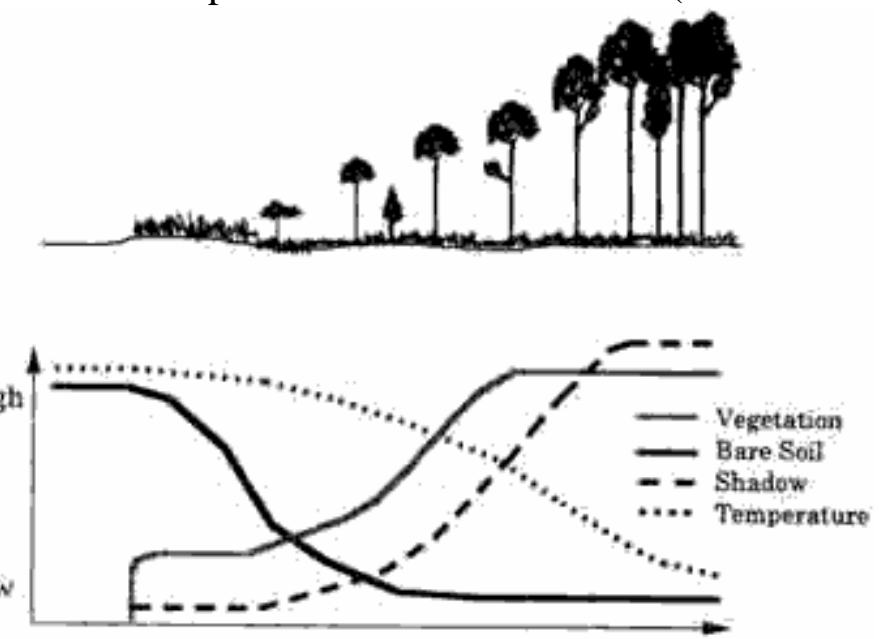

Fig. 1: The Characteristics of four indeces for forest condition

As the FCD value increase there is a corresponding increase in the SI value. In other words where there is more tree vegetation there is more shadow. Concurrently, if there is less bare soil (i.e. a lower BI value) there will be a corresponding decrease in the TI value. It should be noted that VI is "saturated" earlier than SI. This simply means that the maximum VI values that can be regardless of the density of the trees or forest. On the other hand, the SI values are primarily dependent on the amount of tall vegetation such as tree which cast a significant shadow (Rikimaru and Miyatake 1997).

Table 1: Combination Characteristics between Four Indices

\begin{tabular}{|c|c|c|c|c|}
\hline Index & Hi-FCD & Low-FCD & Grass-Land & Bare Land \\
\hline AVI & Hi & Mid & Hi & Low \\
\hline BI & Low & Low & Low & Hi \\
\hline SI & Hi & Mid & Low & Low \\
\hline TI & Low & Mid & Mid & Hi \\
\hline
\end{tabular}

\section{STUDY AREA AND DATA SOURCE}

The study area is located at the two nature reserves in West Java, Mt. Simpang and Mt. Tilu Nature Reserves $\left(107^{\circ} 25^{\prime} 15^{\prime \prime}-107^{\circ} 26^{\prime} 12^{\prime \prime} \mathrm{E}\right.$ and $\left.7^{\circ} 20^{\prime} 21^{\prime \prime}-7^{\circ} 21^{\prime} 13^{\prime \prime} \mathrm{S}\right)$. Both reserves are located in the border of Bandung, Garut and Cianjur.

The data used for this research were remote sensing imageries and vector-based topographic data to derive Digital Elevation Model (DEM). The source materials of remote sensing are

TS 21 - Taxation and Valuation $3 / 9$

Firman Hadi, Ketut Wikantika and Irawan Sumarto

TS21.4 Implementation of Forest Canopy Model to Monitor Forest Fragmentation in Mt. Simpang and Mt. Tilu Nature Reserves, West Java, Indonesia

$3^{\text {rd }}$ FIG Regional Conference

Jakarta, Indonesia, October 3-7, 2004 
Landsat GeoCover, downloaded from the ftp site of Global Land Cover Facility (ftp://ftp.glcf.umiacs.umd.edu) while the topographic data is from Bakosurtanal.

The Landsat GeoCover dataset is a collection of high-resolution satellite imagery provided in a standardized, orthorectified format or, in other words, corrected for terrain displacement and errors in image geometry. In addition to this georeferencing information, GeoCover image file from the GLCF will have been processed using a nearest-neighbor resampling technique (although no interpolation was used). These characteristics are listed in the metadata file accompanying the scene. Most of these characteristics can be converted to other format options, depending on need and software.

\section{METHODOLOGY}

\subsection{Image Pre-processing}

The satellite image was already geo-rectified by the GLCF so the image rectification was not necessary. The river vector map was overlaid on the image just to validate it visually.

\subsection{Image Processing Software}

GRASS 5.3.0 was used as the image processing software in this research.

\subsection{Procedures}

The process and steps involved in calculating Forest Canopy Density Model are given as below (Rikimaru and Miyatake, 1997):

\subsection{1 $\quad$ Advanced Vegetation Index (AVI)}

When assessing the vegetation status of forests, the new methods first examine the characteristics of chlorophyll-a using a new Advanced Vegetation Index (AVI) that is calculated with the following formulae.

$$
\begin{aligned}
& \text { B1 B7: TM Band 1 7 data } \\
& \text { B43=B4-B3 after normalization of the data range. } \\
& \text { CASE-a B43<0 AVI= } 0 \\
& \text { CASE-b B43>0 AVI=((B4+1)x }(256-B 3) \times \text { B } 43) 1 / 3
\end{aligned}
$$

\subsubsection{Bare Soil Index (BI)}

The value of the vegetation index is not so reliable in situations where the vegetation covers less than half of the area. Fore more reliable estimation of the vegetation status, the new methods include a bare soil index (BI) which is formulated with medium infrared information. The underlying logic of this approach is based on the high reciprocity between bare soil status and vegetation status. By combining both vegetation and bare soil indices in the analysis, one may assess the status of forest lands on a continuum ranging from hi

TS 21 - Taxation and Valuation $4 / 9$ Firman Hadi, Ketut Wikantika and Irawan Sumarto TS21.4 Implementation of Forest Canopy Model to Monitor Forest Fragmentation in Mt. Simpang and Mt. Tilu Nature Reserves, West Java, Indonesia

$3^{\text {rd }}$ FIG Regional Conference

Jakarta, Indonesia, October 3-7, 2004 
vegetation conditions to exposed soil conditions.

$$
\begin{aligned}
& \mathrm{B} 1=((\mathrm{B} 5+\mathrm{B} 3)-(\mathrm{B} 4+\mathrm{B} 1)) /((\mathrm{B} 5+\mathrm{B} 3)+(\mathrm{B} 4+\mathrm{B} 1)) \times 100+100 \\
& ; 0<\mathrm{BI}<200 \\
& \text { The range of } \mathrm{BI} \text { is covered within } 8 \text { bits range }
\end{aligned}
$$

\subsubsection{Shadow index (SI)}

One unique characteristic of a forest is its three dimensional structure To extract information on the forest structure from RS data, the new methods examine the characteristics of shadow by utilizing (a) spectral information on the forest shadow itself and (b ) thermal information on the forest influenced by shadow.

The shadow index is formulated through extraction of the low radiance of visible bands.

$$
\mathrm{SI}=((256-\mathrm{B} 1) \times(256-\mathrm{B} 2) \times(256-\mathrm{b} 3))^{1 / 3}
$$

\subsubsection{Thermal Index (TI)}

Two (s) factors account for the relatively cool temperature inside a forest. One is the shielding effect of the forest canopy which blocks and absorbs energy from the sun. The other is evaporation from the leaf surface which mitigates warming. Formulationof the thermal index is based on these phenomenon. The source of thermal information is the infrared band of TM data.

\section{RESULTS AND DISCUSSION}

These are the results figures of each steps in implementing the Forest Canopy Density Model:

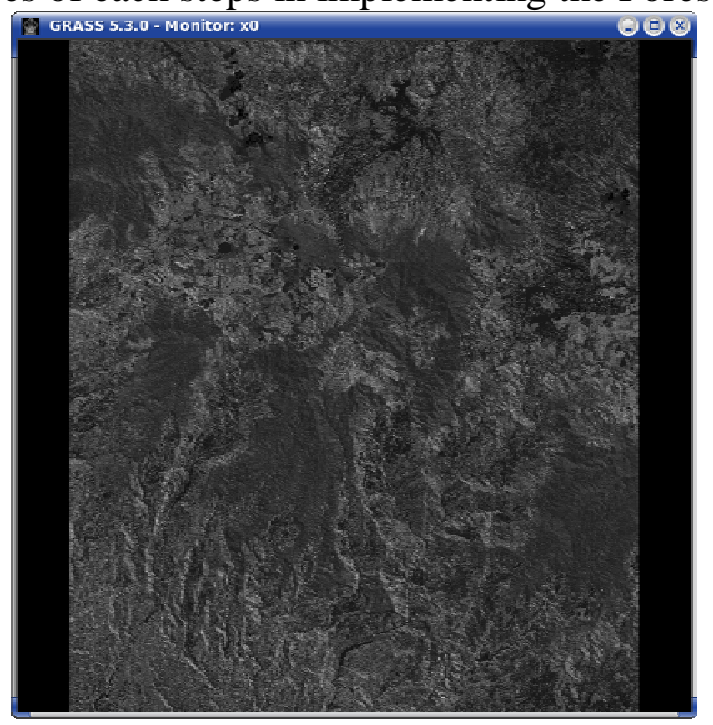

Figure 2: Advanced Vegetation Index

TS 21 - Taxation and Valuation

Firman Hadi, Ketut Wikantika and Irawan Sumarto

TS21.4 Implementation of Forest Canopy Model to Monitor Forest Fragmentation in Mt. Simpang and Mt. Tilu Nature Reserves, West Java, Indonesia

$3^{\text {rd }}$ FIG Regional Conference

Jakarta, Indonesia, October 3-7, 2004 


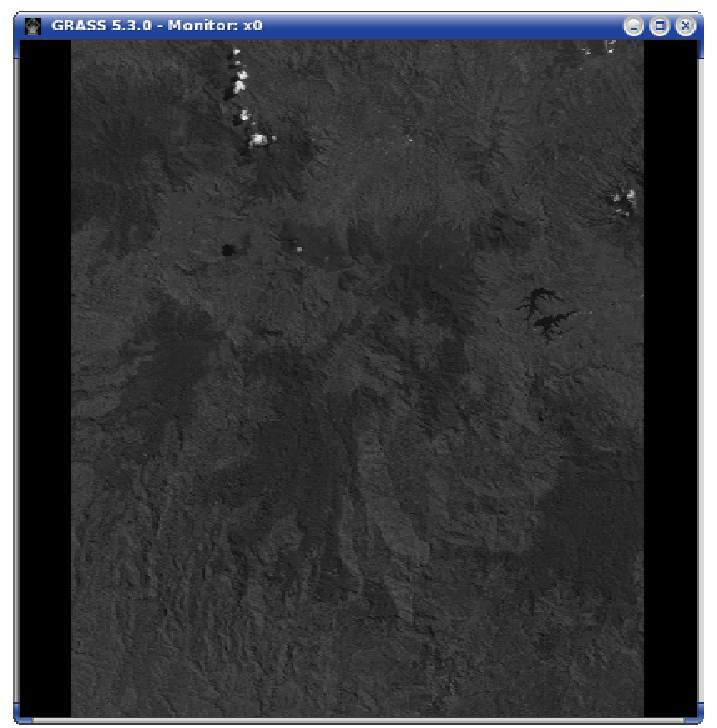

Figure 3: Baresoil Index

Figure 2 shows that darker color represent areas which have a higher Advanced Vegetation Index while Figure 3 describes the opposite, the darker the image the more closed the canopy of its vegetation.

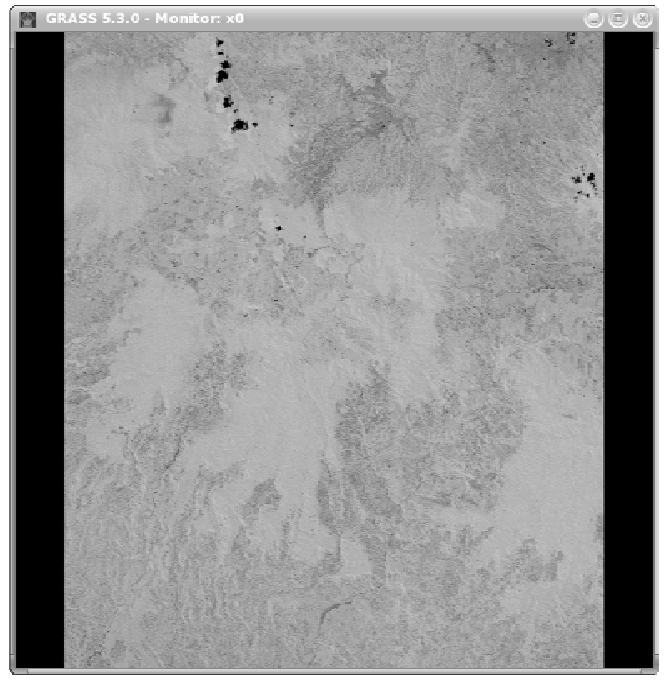

Figure 4: Shadow Index 


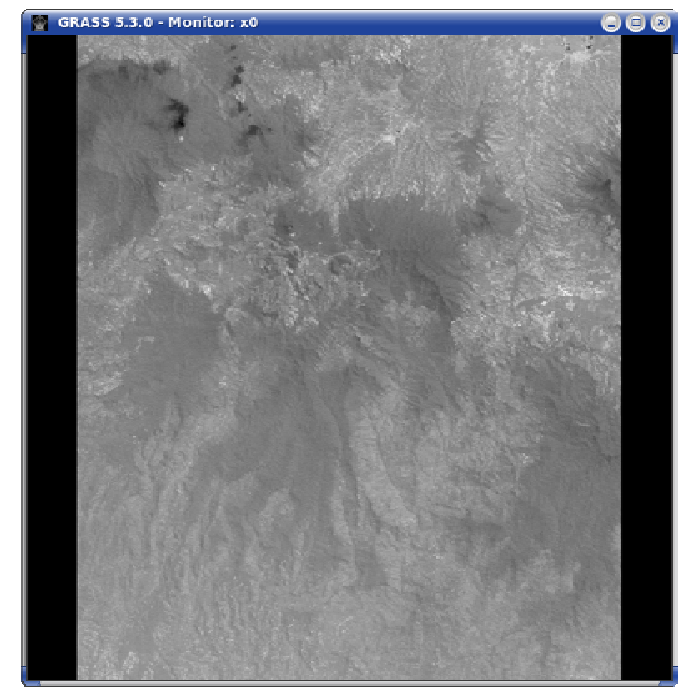

Figure 5: Temperature Index

Figure 4 shows area with more shadows (higher shadow index) in lighter color than the surrounding areas. Figure 5 shows areas with cooler temperature (lower temperature index) with darker color.

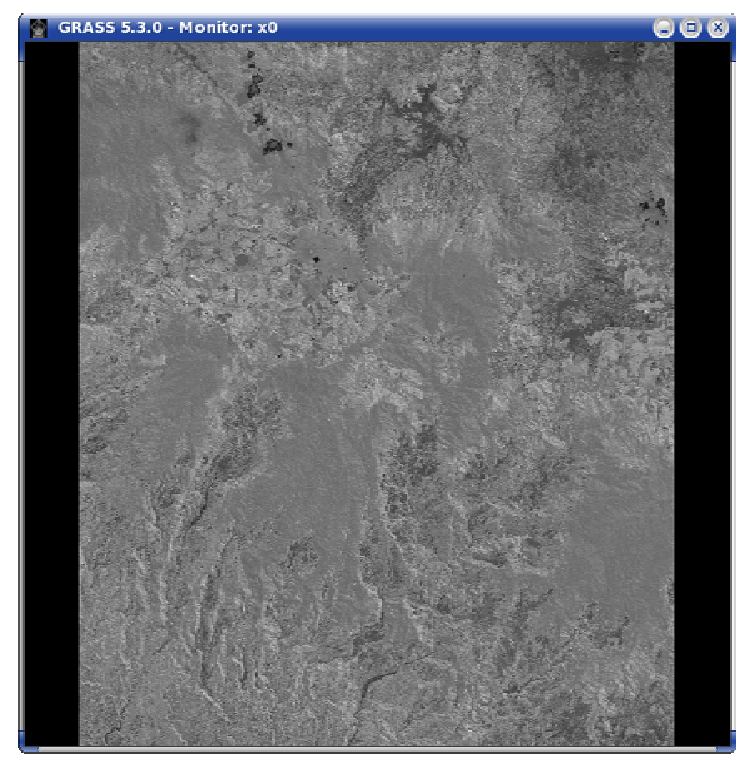

Figure 6: Forest Canopy Density

Figure 6 shows areas with greater value of forest canopy density index in lighter color. The major habitat of the areas as shown in Figure 6 is natural forests. They have forest canopy density index value around $40-50 \%$. The FCD model was able to detect the canopy density of natural forest within one type of ecosystem but it was not able to differentiate the canopy density of two type of ecosystem. The result shows that the teak plantation have higher value of forest canopy density index than natural forests $(>60 \%)$.

TS 21 - Taxation and Valuation $7 / 9$

Firman Hadi, Ketut Wikantika and Irawan Sumarto

TS21.4 Implementation of Forest Canopy Model to Monitor Forest Fragmentation in Mt. Simpang and Mt. Tilu Nature Reserves, West Java, Indonesia

$3^{\text {rd }}$ FIG Regional Conference

Jakarta, Indonesia, October 3-7, 2004 


\section{CONCLUSION}

The Forest Canopy Density Model can be used to detect the forest health via the percentage of canopy closures. The implementation of this model to monitor the forest closures is relatively quick and easy but also has certain limitations. This approach is not able to differentiate the canopy density of two different type of vegetation (e.g. teak plantation and natural forest).

\section{ACKNOWLEDGEMENT}

The author wish to acknowledge the Global Land Facility Cover which provides Landsat imageries freely for the public. Without the imagery this research would never have been done. The acknowledgement would also goes to all of the lecturers in Department of Geodetics Engineering and Geomatics who have provided the author so much knowledge. The author would also to give a special appreciation to Wawang Yulibrata for being so patient in life.

\section{REFERENCES}

Rikimaru, A., S. Miyatake, P. Dugan. 1999. Sky is the Limit for Forest Management Tool. ITTO Tropical Forest Update 9/3. p. 6-9.

Roy, P.S., S. Miyatake., A.Rikimaru. 1997. Biophysical Spectral Response Modeling Approach for Forest Density Stratification. http://www.gisdevelopment.net/ aars/acrs/1997/ts5/ts5008.shtml

Rikimaru, A., S. Miyatake. 1997. Development of Forest Canopy Density Mapping and Monitoring Model Using Indices of Vegetation, Bare Soil and Shadow. http://www.gisdevelopment.net/aars/acrs/1997/ts5/ts5006.shtml

\section{BIOGRAPHICAL NOTES}

Firman Hadi, S.Si., received the bachelor degree in Biology from Padjadjaran University, Bandung Indonesia, in 2001. Since 1999, he has been actively joined the environmental organization to protect the Indonesian forest. To improve his knowledge in GIS and Remote Sensing, since August 2002 he has been registered as the post-graduate student of Geomatics in Department of Geodetics Engineering and Geomatics, Institute Technology of Bandung, Indonesia.

Ketut Wikantika, Dr. Ir. M.Eng, received the Ph.D degree in 2001 from Chiba University, Japan, in remote sensing. He joined Institute of Technology Bandung as a lecturer in the Department of Geodetic Engineering and became an Associate Professor in 2004. His research interest is in environmental remote sensing from local to regional scales.

TS 21 - Taxation and Valuation

Firman Hadi, Ketut Wikantika and Irawan Sumarto

TS21.4 Implementation of Forest Canopy Model to Monitor Forest Fragmentation in Mt. Simpang and Mt. Tilu

Nature Reserves, West Java, Indonesia

$3^{\text {rd }}$ FIG Regional Conference

Jakarta, Indonesia, October 3-7, 2004 


\section{CONTACTS}

Firman Hadi, Ketut Wikantika and Irawan Sumarto

Department of Geodetic Engineering

Institute of Technology Bandung (ITB)

Jalan Ganesha 10 Bandung 40132

INDONESIA

Tel. + 62222530701 ext. 3644

Fax + 62222530702

Email: parmin@nerdshack.com, ketut@gd.itb.ac.id 